\title{
The thermal peak: A simple stream temperature metric at regional scale
}

\author{
Aurelien Beaufort ${ }^{1,2}$, Jacob S. Diamond ${ }^{1,2}$, Eric Sauquet ${ }^{1,}$ Florentina Moatar $^{1 *}$ \\ ${ }^{1}$ RiverLy, INRAE, Centre de Lyon-Grenoble Auvergne-Rhône-Alpes, France 69100 \\ 5 '2Université de Tours, GéoHydrosystèmes COntinentaux, Tours, France 38000 \\ Correspondence to: Florentina Moatar (florentina.moatar@inrae.fr)
}

\begin{abstract}
Spatiotemporally comprehensive stream temperature datasets are rare because interest in these data is relatively recent and there is little money to support instrumentation at regional or national scales. This lack of data has been recognized as a major limitation for understanding thermal regimes of riverine ecosystems. To overcome these barriers, we first aggregated one of the largest stream temperature databases on record with data from 1700 individual stations over nine years from 2009-2017 ( $n=45,000,000$ hourly measurements) across France $\left(\right.$ area $\left.=552,000 \mathrm{~km}^{2}\right)$. For each station, we calculated a simple, ecologically relevant metric-the thermal peak-that captures the magnitude of summer thermal extremes. We then used three statistical models to extrapolate the thermal peak to nearly every stream reach in France and Corsica $(n=105,800)$ and compared relative model

15 performances among each other and with an air temperature proxy. In general, the hottest thermal peaks were found along major rivers, whereas the coldest thermal peaks were found along small rivers with forested riparian zones, strong groundwater inputs, and which were located in mountainous regions. Several key predictors of the thermal peak emerged, including drainage area, mean summer air temperature, minimum monthly specific discharge, and vegetation cover in the riparian zone. Despite differing predictor importance across model structures, we observed strong concordance among models in their spatial distributions of the thermal peak, suggesting its robustness as a useful metric at the regional scale. However, air temperature was a poor proxy for the stream temperature thermal peak across nearly all stations and reaches, highlighting the growing need to measure and account for stream temperature in regional ecological studies.
\end{abstract}

\section{Introduction}

Stream temperature is a master variable affecting ecosystem processes in lotic systems. It controls the solubility of gases and related biogeochemical reactions, regulates metabolism (Wolter, 2007), nutrient cycling (Malard et al., 2002), and decomposition rates, and dictates animal ingestion and digestion rates (Elliott, 1976), reproduction cycles (Daufresne et al., 2004), and mobility (Ojanguren and Brañta, 2000). Stream temperature can also be a source of stress and mortality for aquatic organisms, especially when coupled to additional stressors like low water levels (Miller et al., 2007). Consequently, the dynamics of populations and communities, their relative composition (Kishi et al., 2005) and their size structure (Daufresne et al., 2009) are intimately related to stream thermal regimes. Climate change threatens freshwater ecosystems through multiple pathways, but rising stream temperatures and reduced flows and levels may be most common and deleterious for aquatic organisms. In particular, many ectotherm species are unlikely to tolerate warmer environmental conditions (Tisseuil et al., 2012). In response, cold-water fish species will likely shift towards higher latitudes and altitudes, while warm-water species will likely expand their geographical distribution (Heino et al., 2009). However, the magnitude and direction of these 
expected changes will depend strongly on patterns of stream temperature change, which is currently poorly constrained. Hence, it is critical to describe and analyze the spatiotemporal variability of river thermal regimes. The five main components of stream thermal regimes comprise temperature magnitude, frequency, duration, rate of change, and timing, with different metrics to quantify the biological or ecological importance of each component (Steel et al., 2017; Olden and Naiman, 2010; Tsang et al., 2016). However, these metrics can be accurately determined only if continuous time series of stream temperature are available (Jones and Schmidt, 2018).

Although recent advancements in in-situ sensor technology have greatly expanded stream temperature data availability (Isaak et al., 2017) there is still a lack of long-term data for the vast majority of stream reaches, limiting understanding of thermal regimes at river network and regional scales (Arismendi et al., 2014). In addition, stream temperature data collection is often spatiotemporally uncoordinated across regions and river networks, resulting in snapshot datasets that are regularly supported or replaced with air temperature proxies in aquatic ecology studies (Conti et al., 2015; Logez et al., 2012; Tisseuil et al., 2012). While air temperature can be used to fill data gaps (Buisson and Grenouillet, 2009; Durance and Ormerod, 2009), air temperature is a poor surrogate for stream temperature in several cases. In particular, air temperature correlates poorly with stream temperature in headwater reaches (Caissie, 2006), in reaches with strong local controls (e.g., riparian vegetation, groundwater inflows, bed form, impoundements), and in reaches with large environmental heterogeneity (Moatar and Gailhard, 2006; Hill and Hawkins, 2014; Loicq et al., 2018; Chandesris et al., 2019; Seyedhashemi et al., 2021). Hence, using air temperature metrics to study climate change impacts on the aquatic species distributions may result in misguided inference and consequent management decisions.

In addition to air temperature proxies, many studies have turned to regionalized deterministic and statistical models to fill stream temperature data gaps (e.g. Mohseni et al., 1998; Segura et al., 2015; Chang and Psaris, 2013; Beaufort et al., 2016; Westhoff et al., 2007; Yearsley, 2012). Deterministic models rely on a physically based formulation of stream energy conservation to compute water temperature (Yearsley, 2012; van Vliet et al., 2012; Beaufort et al., 2016). However, such models suffer from large data requirements leading to a preference for statistical approaches, especially in ungauged catchments. Some of these approaches empirically relate stream temperature to climatic and environmental variables, such as air temperature, discharge, altitude or channel width (Benyahya et al., 2007; Moore et al., 2013). Other statistical methods include lumped regression-based models (Daigle et al., 2010; Ducharne, 2008; Hrachowitz et al., 2010; Bustillo et al., 2014), distributed stream-network models (Detenbeck et al., 2016; Isaak et al., 2017), and machine learning methods (Chenard and Caissie, 2008; DeWeber and Wagner, 2014). Still, these approaches often have dense spatial data requirements and their estimates are usually temporally limited (Isaak et al., 2010; Pratt and Chang, 2012; Hill et al., 2013). Indeed, few studies estimate stream temperature over a full year, likely because of non-linear relationships and seasonal hysteresis between air and stream temperature, missing data, and autocorrelation (Jackson et al., 2018; Letcher et al., 2016; Sohrabi et al., 2017). However, for management purposes in the context of climate change, annual stream temperature patterns may be unnecessary. Indeed, stream temperature metrics that focus on extreme periods (e.g., summer) are likely adequate to understand trends of increasing pressures on aquatic ecosystems.

To that end, our objective here is to develop empirical statistical models to predict a simple, ecologically relevant stream thermal metric that captures the magnitude of the stream temperature extremes at the regional scale. To do so, we first define an interannual thermal metric, which we term the "thermal peak", using heterogeneous and nonconcomitant time series of stream temperature and estimate it at 1,700 stations for 2009-2017. We then test three 
statistical models and one multi-model approach to predict this metric at the regional scale and compare their predictive capacity with that of air temperature.

\section{Methods}

80

\subsection{Study area and monitoring network}

The study area is continental France and Corsica $(550,000 \mathrm{~km} 2)$. France is located in a temperate zone characterized by a variety of climates due to the influences of the Atlantic Ocean, the Mediterranean Sea, and mountain areas.

We assembled the most exhaustive stream temperature dataset in France to date by combining data from both public (national, regional) and private managers (fishermen associations). Due to the diversity of station ownership, the assembled times series do not have a consistent spatial and temporal structure. Some regions are densely monitored while others have few instrumented streams and much of the data do not exhibit temporal overlap, challenging our ability to define comparable metrics among streams. Hence, our main challenge was to pool the maximum of observation stations to optimize the number of monitored streams while dealing with the non-continuous observation periods of the stations. The large spatial and temporal heterogeneity of the monitoring data precluded application of spatial autocorrelation methods, and we have therefore chosen to consider only nonspatial statistical models.

The stream temperature data used here comprise approximately $45,000,000$ hourly measurements from 1,700 unique measurement stations ( $\mathrm{n}=2,107,623$ site-days) collected between 2009 and 2017, primarily during summer. All the stations under strong human influence (i.e., dam releases and nuclear power thermal effluent) and stations without seasonal dynamics were previously excluded from this data set. All data were recorded by automatic data loggers managed by professional biologists or hydrologists. Outliers from each station's time series were removed with automatic outlier detection filters and the resulting data were screened visually before being averaged into mean daily stream temperature data (hereafter referred to as $T_{w}$ ). The automatic outlier detection consists of three steps with eight unique filters that remove, in order, 1) hourly $T_{w}$ anomalies, 2) monthly anomalies between $T_{w}$ and $\mathrm{T}_{\text {air }}$, and 3) daily anomalies between $\mathrm{T}_{\mathrm{w}}$ and $\mathrm{T}_{\text {air }}$ (Moatar et al., 2001; Beaufort et al., 2020b).

To address ecologically meaningful temperature metrics under climate change, we focused on the two hottest stream temperature months, July and August (hereafter referred to as summer), a time period essential for the growth and survival of many aquatic species. This focus also has the benefit of maximizing the number of observation stations for analysis. Still, out of the 1700 stations, 490 stations have just one year of data, 88 stations have observations covering summer over all nine years, and only 30 have year-round observations for all nine years (Figure 1a,b). To obtain hydraulic and hydrologic characteristics for each station, stations were projected onto the Theoretical Hydrographic Network for France (RHT; Pella et al., 2012), an oriented hydrographic network with defined flow directions that comprsies 114,600 reaches of median length 1,961 m (2,475 $\pm 1,512 \mathrm{~m}$, mean $\pm \mathrm{sd})$. A majority of stations were located on RHT river reaches with drainage areas $20-500 \mathrm{~km}^{2}$, whereas most reaches are small streams with a drainage area of less than $20 \mathrm{~km}^{2}$ (Figure 1c). 
a

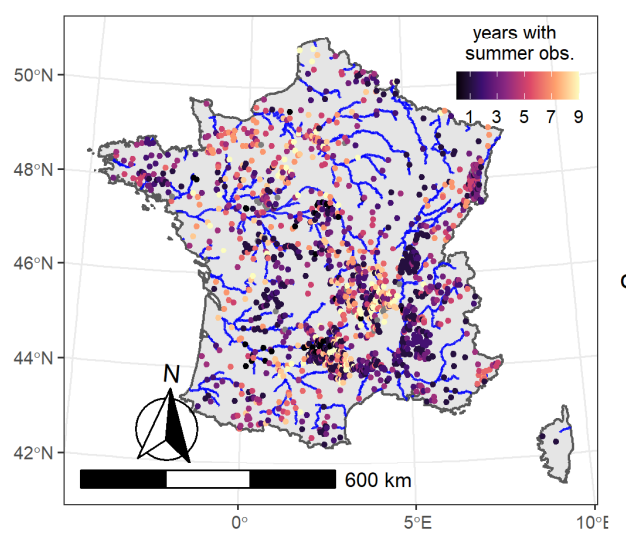

b
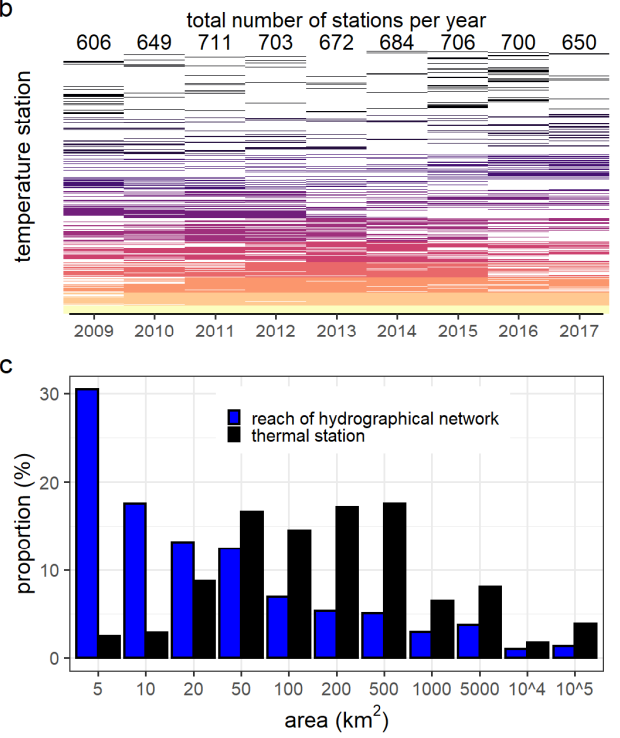

Figure 1. Data availability for each temperature station used in this study. a) Map of stream temperature stations in France with RHT network shown for all reaches of Strahler order $>4$, and b) Heatmap of data availability by year (x-axis) and station (y-axis) with the total stations per year listed at the top of each column. Sites are colored by the number of years with observations. c) Distributions of drainage area for RHT reaches (blue) and of thermal stations (black).

\subsection{Defining the thermal peak stream temperature metric}

Due to the limited concordance among stream temperature time series (Figure 1b) and to focus our analysis towards ecologically relevant ends, we summarized our stream temperature data with a simple metric. This kind of metric has precedent in regional species distribution models that instead used air temperature (hereafter referred to as $\mathrm{T}_{\text {air }}$ ) as a proxy (Buisson and Grenouillet, 2009).

We refer to this metric as the thermal peak $\left(T_{p}\right)$, and define it as the interannual average of the mean temperature of the 30 hottest consecutive days of each year $\left(\overline{T_{w, 30}}\right)_{i}$ :

$$
T_{p}=\frac{\sum_{i=1}^{N}\left(\overline{T_{w, 30}}\right)_{i}}{N}
$$

Where $\mathrm{i}=$ year index; and $\mathrm{N}=$ the number of years of observation available from 2009-2017 ( $\mathrm{N}=1-9)$. Across sites, the hottest day of the year always occurred within the approximate 30 day period between July 28 and August 30 (mean \pm sd: August $12 \pm 16$ days), lending support to this focused approach.

\subsection{Climate correction of the thermal peak}

130 The thermal peak can be biased depending on the climatic variability of the years of observation for each station. Indeed, only 30 of our stations have $\mathrm{T}_{\mathrm{p}}$ calculated using all nine years of data, and therefore have the highest level of confidence in their estimate. We refer to the $T_{p}$ from these 30 stations as $T_{p, r e f}$, indicating that these are reference, 
or true estimates of $\mathrm{T}_{\mathrm{p}}$ (Table 1). To account for the bias associated with missing data at the remaining 1670 stations, we gap-filled missing data at these stations using site-specific stream-air temperature regressions. This method accounts for interannual variation in climatic forcing on stream temperature, and we therefore refer to it as a climate correction.

The climate correction is achieved by first calculating station-specific regressions between daily $\mathrm{T}_{\mathrm{w}}$ and a rightaligned moving average of daily $\mathrm{T}_{\text {air }}$ at lags ranging from 2-10 days. The moving average lag whose regression produced the highest coefficient of determination was then used to fill gaps in the time series of $\mathrm{T}_{\mathrm{w}}$ for each station. Next, we reconstructed summer stream temperature using this regression and subsequently recalculated $\mathrm{T}_{\mathrm{p}}$ based on this reconstructed data. We refer to $\mathrm{T}_{\mathrm{p}}$ from these climate-corrected data as $\mathrm{T}_{\mathrm{p}, \mathrm{clim}}$ to indicate that missing data were gap-filled with the climate correction procedure (Table 1).

To validate this approach, we conducted a permutation test on the 30 stations with full annual monitoring from 2009-2017 (i.e., sites where a $T_{p, r e f}$ is known). At each site, we introduced randomly placed, artificial annual gaps into observed data ranging from 1-9 years to simulate missing data. We then backfilled these introduced gaps according to the climate correction method. Following gap-filling, we calculated two metrics: 1) $T_{p}$ using gapinduced data without gap-filling $\left(\mathrm{T}_{\mathrm{p}, \text { gap }}\right)$, and 2$)$ the thermal peak using the gap-filled data $\left(\mathrm{T}_{\mathrm{p}, \text { fill }}\right.$; Table 1$)$. We then compare these two metrics to the reference thermal peak $\left(\mathrm{T}_{\mathrm{p}, \mathrm{ref}}\right)$ using absolute biases at each tested permutation (i.e., the number of introduced gap years). This approach allowed us to assess whether the climate-corrected reconstruction of the gaps in time series is 1) a useful approach, and 2) lower in bias and uncertainty compared to using observed data alone.

Table 1. List of thermal peak terminology with the count of days (n) used in their calculation

\begin{tabular}{|c|c|c|}
\hline Notation & Definition & $\mathbf{n}$ \\
\hline $\mathrm{T}_{\mathrm{p}, \mathrm{obs}}$ & $\begin{array}{l}\text { thermal peak, or the interannual average of the mean temperature of the } \\
30 \text { hottest consecutive days of each year for station with observations }\end{array}$ & 1700 \\
\hline $\mathrm{T}_{\mathrm{p}, \mathrm{ref}}$ & thermal peak for reference stations with all nine years of data & 30 \\
\hline $\mathrm{T}_{\mathrm{p}, \mathrm{clim}}$ & $\begin{array}{l}\text { thermal peak for stations with less than nine years of data to which } \\
\text { climate correction was applied }\end{array}$ & 1670 \\
\hline$T_{\text {p,gap }}$ & thermal peak for reference stations with introduced data gaps & 30 \\
\hline $\mathrm{T}_{\mathrm{p}, \mathrm{fill}}$ & $\begin{array}{l}\text { thermal peak for reference stations whose introduced data gaps were } \\
\text { filled with climate correction }\end{array}$ & 30 \\
\hline $\mathrm{T}_{\mathrm{p}, \mathrm{m}}$ & $\begin{array}{l}\text { modeled thermal peak using statistical extrapolation to the RHT network } \\
\text { using statistical method } \mathrm{m}\end{array}$ & 114,600 \\
\hline$T_{\text {p.air }}$ & thermal peak estimated using the air temperature proxy & 114,600 \\
\hline
\end{tabular}

\subsection{Extrapolating the thermal peak to national scale with statistical modeling}

We estimated $\mathrm{T}_{\mathrm{p}}$ throughout the entire RHT network using four distinct statistical models. For modeling $\left(\mathrm{T}_{\mathrm{p}, \mathrm{m}}\right)$ it

is not clear how to choose a priori a particular model structure due to the complexity of the processes involved in determining local stream temperature. Therefore, we tested four different structures: 1) a multiple linear regression model (REG), 2) an artificial neural network model (ANN) that is potentially non-linear, but encompasses a linear model as a special case, 3 ) a random forest model (RF) that can also be non-linear, but with a different strategy than ANN, and 4) a multi-model combination (MM), which combines the three prior structures ANN, RF, and REG. All these models are based on a function to estimate $\mathrm{T}_{\mathrm{p}}$ at all stations (i):

$$
T_{p, m, i}=f\left(g_{1, i}, \ldots, g_{n, i}\right)
$$

Where $\mathrm{g}_{\mathrm{n}, \mathrm{i}}=$ the $\mathrm{nth}$ explanatory variable defined for each ith station. 
To measure how stream thermal regime estimations might be different if using a $T_{\text {air }}$ proxy, we also calculated $T_{p, a i r}$ using $T_{a i r}$ from SAFRAN data. The $T_{p}$,air is calculated identically to $T_{p}$, but using daily $T_{\text {air }}$ instead of daily

$T_{w}$, as would be done in ecological studies using $T_{\text {air }}$ as a proxy for $T_{w}$. Finally, to determine the effect of climate corrections on the full RHT extrapolation, we compared the distribution of $\mathrm{T}_{\mathrm{p}, \mathrm{m}}$ values when models were fit using either $\mathrm{T}_{\mathrm{p}, \mathrm{obs}}$ or $\mathrm{T}_{\mathrm{p}, \mathrm{clim}}$.

\subsubsection{Explanatory variables}

We selected sixteen variables (Table 2) to explain the spatial distribution of $\mathrm{T}_{\mathrm{p}, \mathrm{m}}$ based both on results from a prior analysis (Beaufort et al., 2019), and on a principal component analysis to minimize variable dependencies. We further considered the ability to calculate or estimate each variable at the scale of the entire RHT network. The variables fall into three categories: climate, hydrology, and catchment characteristics.

The four climatic variables were determined from SAFRAN reanalysis data for the years 2009-2017: 1) mean annual precipitation, 2) mean summer precipitation, 3) mean annual snowfall, and 4) mean summer air temperature. The SAFRAN reanalysis data (grid $8 \mathrm{~km}$ ) were available at hourly time step (Quintana-Segui et al., 2008; Vidal et al., 2010) and climatic variables were extracted from the SAFRAN meshes overlapping the station location.

The four hydrological variables were determined by extrapolation based on prior datasets. The first two variables, monthly minimum discharge (Sauquet et al. 2008) and the annual minimum monthly discharge with a return period of five years (Catalogne, 2012), describe the low-flow regime of each site. The remaining two variables, the hydrologic regime (HR; Sauquet et al., 2008) and the concavity index (CI; Sauquet and Catalogne, 2011), are dimensionless and characterize the general hydrology of each site. More specifically, the HR groups sites into one of 12 classes ranging from rainfall-dominated, to transitional, to glacial and snow melt dominated. The CI describes the concavity of the flow duration curve, where values close to 1 indicate low flow variability (e.g., large high storage capacity in aquifer or snow) and values close to 0 indicate high flow variability (e.g., low storage capacity exemplary of Mediterranean systems).

The eight variables relating to catchment characteristics were extracted from either the SYRAH-CE database (Valette et al., 2012) or the RHT database (Pella et al., 2012). The three variables from RHT comprise: 1) mean altitude, 2) catchment drainage area, and 3) mean slope. The five variables from SYRAH-CE comprise: 1) riparian vegetation cover in a $10 \mathrm{~m}$ buffer, 2) linear upstream weir density along the stream, 3) areal upstream weir density for the catchment, 4) upstream pond cover as a fraction of stream area, and 5) incision class describing the rate of incision of the valley.

Table 2. List of explanatory variables used in models.

\begin{tabular}{|c|c|c|c|}
\hline Category & Variable & Notation & Source \\
\hline \multirow{4}{*}{ Climate } & Mean annual precipitation $(2009-2017)[\mathrm{mm}]$ & $\mathrm{P}_{\text {annual }}$ & SAFRAN \\
\hline & Mean summer precipitation, July-August (2009-2017) [mm] & $\mathrm{P}_{\text {summer }}$ & SAFRAN \\
\hline & Mean annual snow accumulation (2009-2017) [mm] & $S_{\text {annual }}$ & SAFRAN \\
\hline & Mean summer air temperature, July-August $(2009-2017)\left[{ }^{\circ} \mathrm{C}\right]$ & $\mathrm{T}_{\text {summer }}$ & SAFRAN \\
\hline \multirow{4}{*}{ Hydrology } & Mean monthly annual minimum discharges with a return period of 5 years* $\left[\mathrm{L} \mathrm{s}^{-1} \mathrm{~km}^{-2}\right]$ & $\mathrm{Q}_{\min }$ & RHT \\
\hline & Mean monthly minimum specific discharge* $\left[\mathrm{L} \mathrm{s}^{-1} \mathrm{~km}^{-2}\right]$ & $\mathrm{q}_{\min }$ & RHT \\
\hline & Concavity index $\uparrow[-]$ & $\mathrm{CI}$ & RHT \\
\hline & Hydrological regime $\neq[-]$ & HR & RHT \\
\hline
\end{tabular}




\begin{tabular}{|c|c|c|c|}
\hline \multirow{8}{*}{$\begin{array}{c}\text { Catchment } \\
\text { characteristics }\end{array}$} & Mean catchment elevation $[\mathrm{m}]$ & elev & RHT \\
\hline & Drainage area $\left[\mathrm{km}^{2}\right]$ & area & RHT \\
\hline & Mean streams slope over the catchment $\left[\mathrm{m} \mathrm{km}^{-1}\right]$ & slope & RHT \\
\hline & Riparian vegetation cover ratio in 10 meters buffer $(\%)^{* *}$ & veg & SYRAH \\
\hline & Linear weir density upstream of stations $\left(\# \mathrm{~km}^{-1}\right)^{* *}$ & weirs & SYRAH \\
\hline & Areal weir density upstream of stations $\left(\# \mathrm{~km}^{-2}\right)^{* *}$ & weir area & SYRAH \\
\hline & Pond cover ratio upstream of stations $(\%)^{* *}$ & ponds & SYRAH \\
\hline & Stream incision class $* *$ & SI & SYRAH \\
\hline
\end{tabular}

\subsubsection{Multiple regression}

We first fit a multiple linear regression model between $\mathrm{T}_{\mathrm{p}}$ and explanatory variables using all possible variables. Prior to fitting, we scaled the explanatory variables so that their fitted coefficients could be compared in terms of relative influence.

\subsubsection{Artificial neural network}

We then used an ANN-specifically a feed-forward neural network with one hidden layer (R package nnet; Venables and Ripley 2002) — to estimate $T_{p}$ as a potentially non-linear function of covariates. We included a direct connection between covariate inputs and outputs so that the case with zero hidden units corresponded to a linear relationship. We used weight decay regularization, also known as ridge regression, to control overfitting by decreasing less relevant coefficients. Both the number of hidden units and the amount of weight decay were selected with a first cross-validation procedure (Bishop, 2006). To quantify the relevance of the different covariates, we used a connection weight approach (Olden and Jackson, 2002; Olden et al., 2004):

$$
W_{V}=\sum_{h=1}^{n h u} A_{V, h} B_{h}
$$

Where $\mathrm{W}_{\mathrm{V}}(-)=$ the relevance of covariate $\mathrm{V}, \mathrm{A}_{\mathrm{V}, \mathrm{h}}(-)=$ the ANN coefficients connecting hidden unit $\mathrm{h}$ to covariate $\mathrm{V}, \mathrm{B}_{\mathrm{h}}(-)=$ the ANN coefficients connecting hidden unit $h$ to the output, and nhu $=$ the number of hidden units.

\subsubsection{Random forest}

We used a random forest for the third statistical model structure, using Breiman's algorithm (Breiman, 2001) with the $\mathrm{R}$ package randomForest (Liaw and Wiener, 2002) allowing 500 trees. The relevance of each predictor variable was provided as standard output by the randomForest package, which determines how much the mean square errors in prediction increases when that covariate is randomly permuted within the tree.

\subsubsection{Multi-model combination}

Finally, we used a multi-model combination approach to obtain a consensus estimation map of $\mathrm{T}_{\mathrm{p}, \mathrm{m}}$. The estimates from each previously described model were linearly combined to reduce the associated uncertainties through multiple linear regression.

$$
T_{\mathrm{p}, \mathrm{mm}}=a T_{\mathrm{p}, \mathrm{ANN}}+b T_{\mathrm{p}, \mathrm{RF}}+a T_{\mathrm{p}, \mathrm{REG}}+d
$$

With $T_{p, m m}=T_{p}$ based on observed and reconstructed $T_{w} ; T_{p, A N N}=T_{p}$ estimated by ANN; $T_{p, R F}=T_{p}$ estimated by $R F ; T_{p, R E G}=T_{p}$ estimated by multiple regression; and a, b, c, $d=$ fitted regression coefficients. 


\subsubsection{Model cross-validation}

To assess model performance prior to spatial extrapolation to the entire RHT network, we conducted a cross-

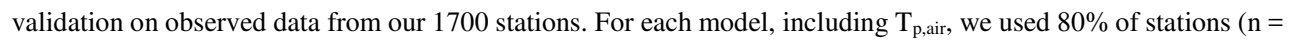
1360) as training data to estimate model parameters. Using those model parameters, we estimated validation data $\mathrm{T}_{\mathrm{p}}$ at the remaining $20 \%$ of stations $(\mathrm{n}=340)$ and cross-validated those estimates with $\mathrm{T}_{\mathrm{p}, \mathrm{obs}}$. We conducted this cross-validation this 100 times allowing for random selection of stations used in the training and validation data sets. We evaluated the results of the cross-validation with the Nash-Sutclife efficiency criterion (NSE, Nash and Sutcliffe, 1970), the RMSE (Root Mean Square Error) and biases between observed $T_{p, o b s}$ and $T_{p, m}$.

\section{Results}

\subsection{Validation of the climate correction approach}

Gap-filling $T_{w}$ with our climate correction approach resulted in consistently lower absolute biases for $T_{p}$ (i.e., $T_{p}$,fill) compared to only using available data (i.e., $\mathrm{T}_{\mathrm{p}, \text { gap }}$ ), regardless of the length of introduced annual gaps (Figure 2). This bias was less than $0.5^{\circ} \mathrm{C}$ for more than $75 \%$ of stations with only one year of observation. In contrast, when there is only one year available, the biases for data with artificial gaps, $\mathrm{T}_{\mathrm{p} \text {,gap }}$, are higher than $0.5{ }^{\circ} \mathrm{C}$ for $75 \%$ of the stations. There was no systematic bias regardless of the years taken into account in the regressions.

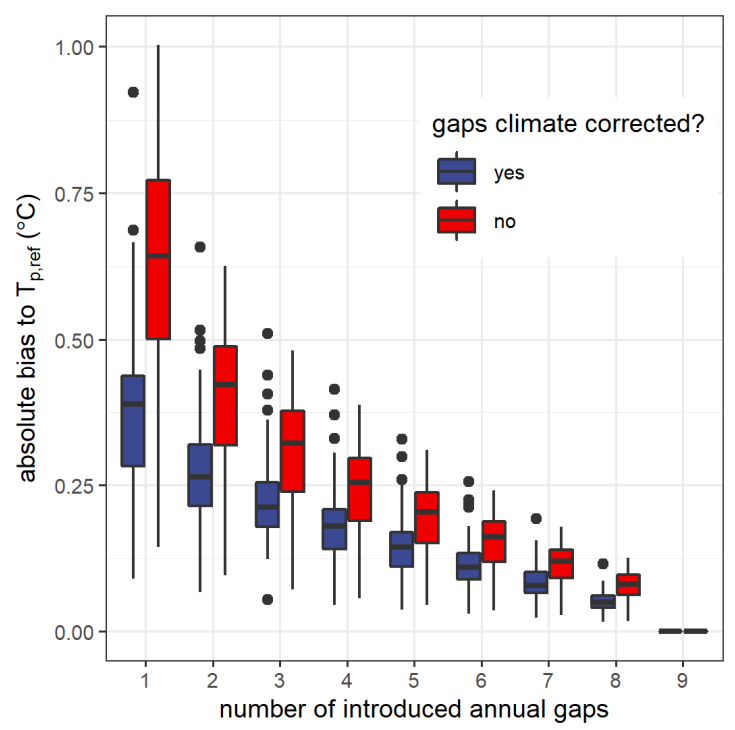

Figure 2. Improvement in absolute bias of thermal peaks across all reference sites $\left(\mathrm{T}_{\mathrm{p}, \mathrm{ref}} ; \mathrm{n}=30\right)$ when introduced annual gaps were filled with the climate correction procedure $\left(\left|T_{p, \text { fill }}-T_{p, r e f}\right|\right.$, red boxplots) compared to when gaps were unfilled $\left(\left|\mathrm{T}_{\mathrm{p}, \mathrm{gap}}-\mathrm{T}_{\mathrm{p}, \mathrm{ref}}\right|\right.$, blue boxplots) regardless of the number of introduced gaps.

\subsection{Model cross-validation}

In cross validation, all four statistical models performed substantially better than air temperature at accurately predicting $\mathrm{T}_{\mathrm{p}}$ (Figure 3). Indeed, $\mathrm{T}_{\mathrm{p} \text {,air }}$ overestimates the observed $\mathrm{T}_{\mathrm{p}, \text { ref }}$ by $2.5^{\circ} \mathrm{C}$ on average (Figure $3 \mathrm{a}$ ), and the 
negative NSE for $T_{p \text {,air }}$ indicates that using a simple mean of $T_{w}$ observations is a better predictor of $T_{p}$ than using $\mathrm{T}_{\text {air }}$ (Figure $3 \mathrm{~b}$ ). Overall, models tend to slightly underestimate $\mathrm{T}_{\mathrm{p}}$ (Figure $3 \mathrm{a}$ ), but mean biases are close to $0^{\circ} \mathrm{C}$. The REG and ANN models had similar performance (median RMSE $>1.5^{\circ} \mathrm{C}$; median NSE $=0.6$ ), whereas the $\mathrm{RF}$ and MM models obtained the best performances (median RMSE $<1.5^{\circ} \mathrm{C}$; median NSE $=0.7$ ) with the MM slightly superior for NSE (Figure 3b,c). We did not observe any spatial patterning in performance metrics (not shown).

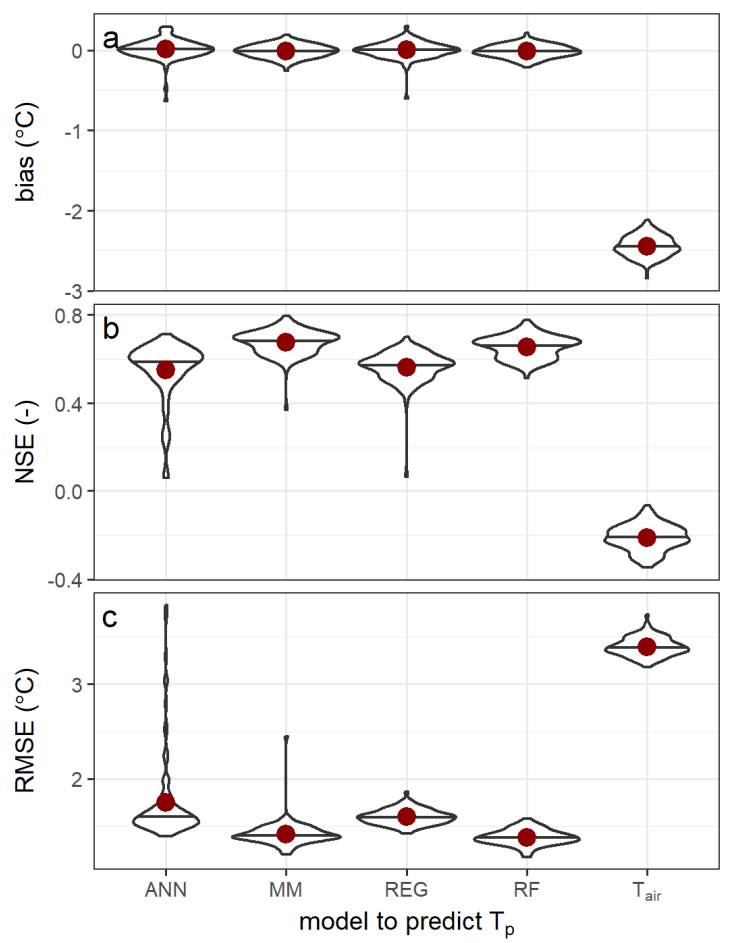

Figure 3. Cross validation performance metrics for modeled thermal peaks $\left(T_{p, m}\right)$, where $80 \%$ of stations $(n=$ $1360)$ were training data and $20 \%$ of stations $(n=340)$ were validation data. Violin plots show distributions of 100 replicates of training-validation data for each model's performance metrics: a) bias relative to $T_{p, r e f ;}$ ) NSE; c) RMSE of $T_{p, m}$ relative to observed $T_{p}$. Horizontal lines indicate sample medians and red points indicate sample means.

\subsection{Relevance of explanatory variables in models}

Explanatory power varied among modeling approaches, and the maximum variance explained for any one variable was between $25-30 \%$. (Figure 4) The two most relevant variables were catchment area (area) and mean summer air temperature $\left(\mathrm{T}_{\text {summer }}\right.$ ) for the RF and multiple regression models (Figure $4 \mathrm{~b}, \mathrm{c}$ ), but were minimum monthly specific discharge ( $\mathrm{q}_{\mathrm{min}}$ ) and riparian vegetation cover (veg) for the ANN model (Figure 4a; $\mathrm{q}_{\mathrm{min}}$ is not correlated with area, $\mathrm{R}^{2}=0$ ). Surprisingly, area and $\mathrm{T}_{\text {summer }}$ obtained relative importances of less than $5 \%$ in ANN whereas they were the most influential variables in the RF and the REG models. It should be noted that the cumulative importance of the four most relevant variables of the REG and ANN models is respectively $92 \%$ and $81 \%$, which 
means that the other variables have very little weight in the estimates. This sum is only $69 \%$ for RF, which indicates that the relative importance of the explanatory variables are more distributed and the other explanatory variables have a significant weight in the estimates which could explain the best performances in cross validation of RF.

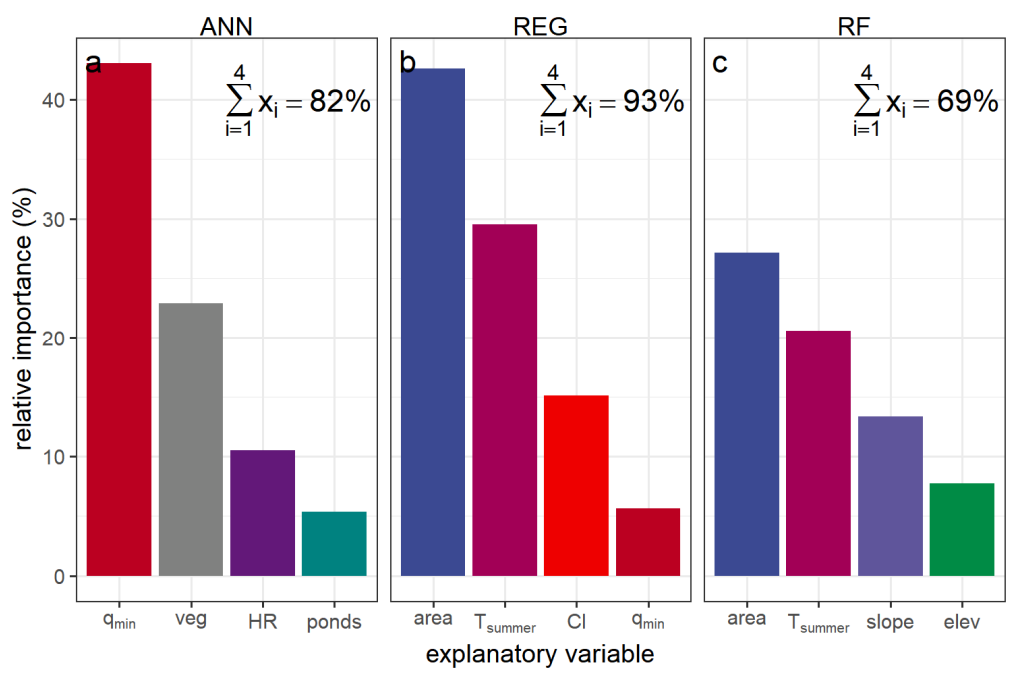

Figure 4. Relative importance of top four explanatory variables calculated in cross validation for the estimation of $\mathrm{T}_{\mathrm{p}}$ with the models: a) ANN; b) REG and c) RF. To compare the relative importance of each variable for each model, all variables were centered and scaled. Text in the upper right of each panel refers to the sum of the relative importances of the first four explanatory variables in each model; colors indicate the explanatory variable.

\subsection{Spatial extrapolation of thermal peaks}

The statistical models could extrapolate $\mathrm{T}_{\mathrm{p}}$ to $92 \%$ (105,800 reaches) of the RHT network, and the resulting spatial structure of the extrapolations was consistent across models (Figure 5). On average, $\mathrm{T}_{\mathrm{p}}$ was $18.2^{\circ} \mathrm{C}$ and ranged between $6.3^{\circ} \mathrm{C}$ and $27.0^{\circ} \mathrm{C}$. The highest $\mathrm{T}_{\mathrm{p}, \mathrm{m}}$ (i.e., $\mathrm{T}_{\mathrm{p}}>22^{\circ} \mathrm{C}$ ) were generally found on the largest rivers located in the southeast and in the sedimentary plains. The lowest $T_{p, m}$ are found in the mountain streams of the Alps, Pyrenees and Massif Central, and in the northwest. Although the distribution $\mathrm{T}_{\mathrm{p}, \mathrm{m}}$ is consistent among models (Figure 5), there are some clear disparities, particularly at the extremes. The ANN model simulates $\mathrm{T}_{\mathrm{p}, \mathrm{m}}$ below $14^{\circ} \mathrm{C}$ on more streams ( $\left.>15 \%\right)$ compared to other models $(<10 \%$; Figure $6 a)$. In stark contrast, estimating $\mathrm{T}_{\mathrm{p}}$ with air temperature (i.e., $\mathrm{T}_{\mathrm{p}, \text { air }}$ ) led to consistently higher values than were obtained with statistical models, with $\mathrm{T}_{\mathrm{p} \text {,air }}$ greater than $20^{\circ} \mathrm{C}$ for more than $70 \%$ of the reaches (Figure $5 \mathrm{a}$, Figure $6 \mathrm{a}$ ).

Application of the climate correction prior to model fitting and subsequent extrapolation showed that differences at the RHT are less than $0.5^{\circ} \mathrm{C}$ at $89 \%$ of the reaches (Figure $6 \mathrm{~b}$ ). Still, $10 \%$ of the reaches exhibited $\mathrm{T}_{\mathrm{p}, \mathrm{m}}$ differences greater than $0.5^{\circ} \mathrm{C}$, and the vast majority of these differences are negative $(9.4 \%$ vs. $1.6 \%)$, suggesting that climate correction more often than not reduces overestimates in $\mathrm{T}_{\mathrm{p}}$. 

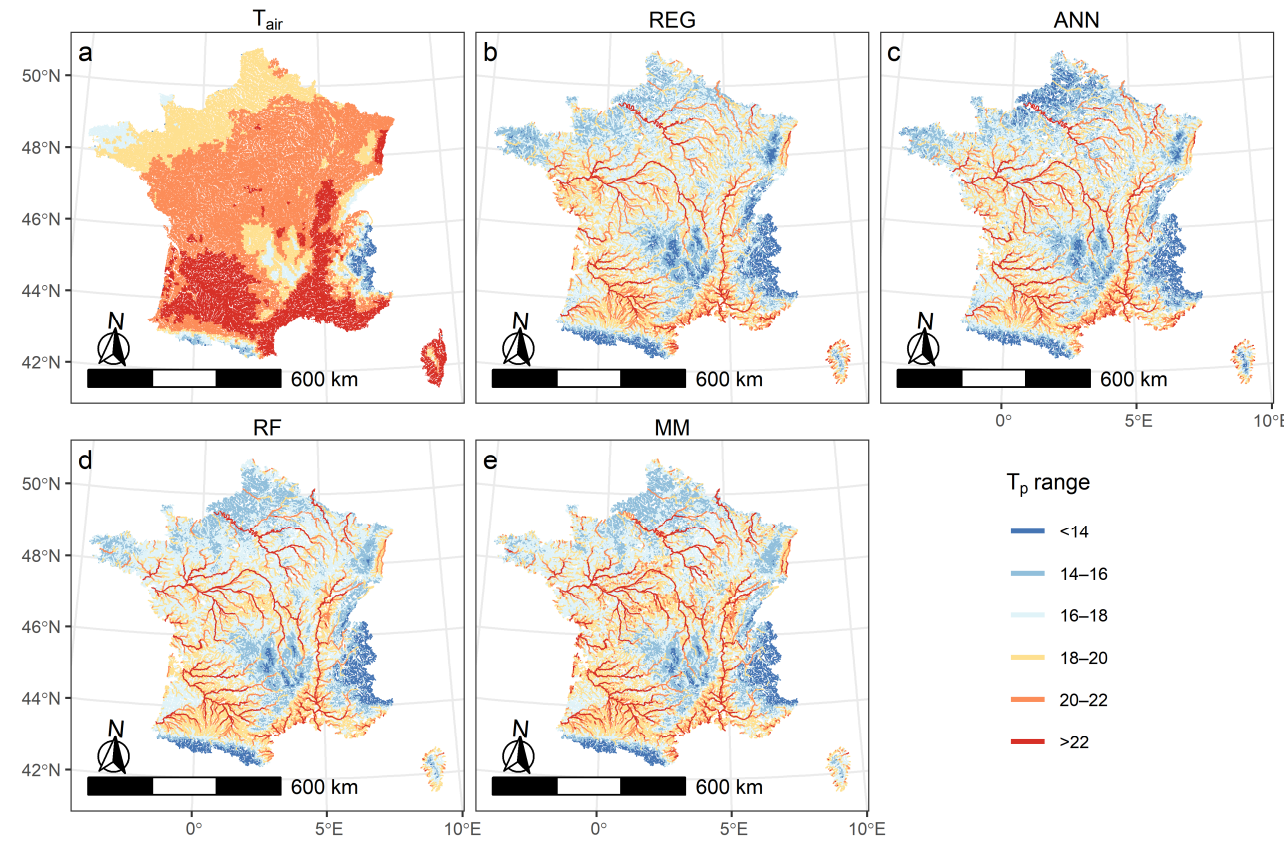

$$
\begin{aligned}
& T_{p} \text { range } \\
& -<14 \\
& -\quad 14-16 \\
& -16-18 \\
& -\quad 18-20 \\
& -\quad 20-22 \\
& ->22
\end{aligned}
$$

Figure 5. Thermal peaks $\left(T_{p}\right)$ of stream water extrapolated to all reaches of the French hydrographical network RHT with the different predictive model structures: a) air temperature $\left.\left(\mathrm{T}_{\text {air }}\right), \mathrm{b}\right)$ multiple regression (REG), c) artificial neural network (ANN), d) random forest (RF), and e) multi-model combination of all previous models (MM). All reaches are colored by their modeled range of $\mathrm{T}_{\mathrm{p}}$.
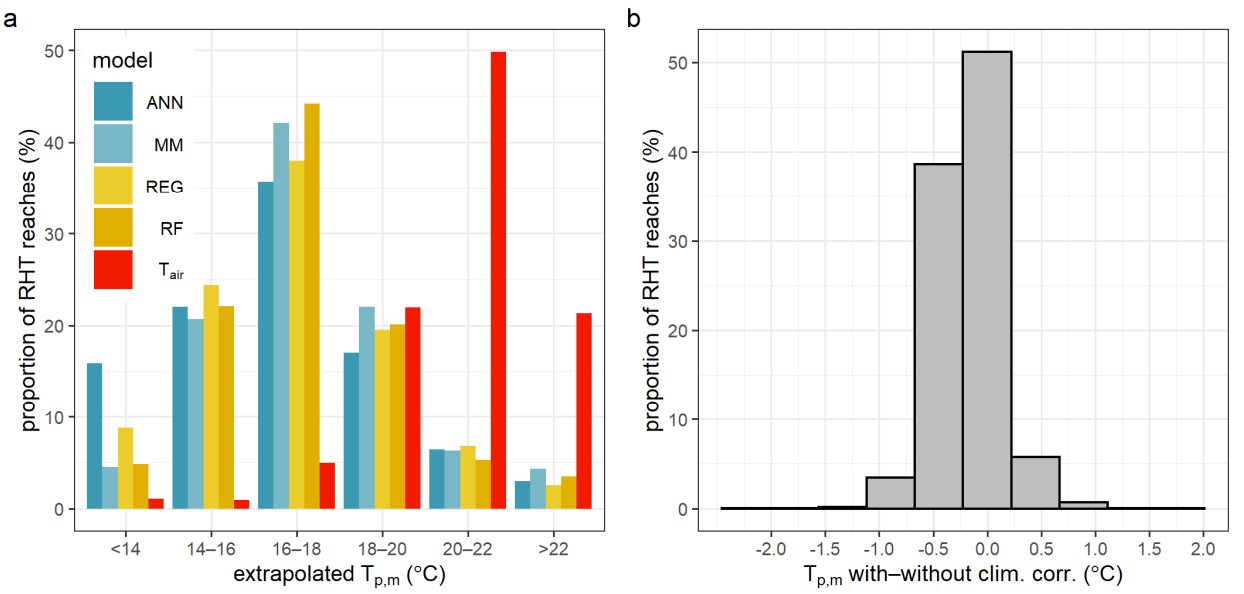

Figure 6. Distributions of $\mathrm{T}_{\mathrm{p}, \mathrm{m}}$ extrapolated to all RHT network reaches. a) Comparison of models according their extrapolated $\mathrm{T}_{\mathrm{p}}$ value, colored by model, and $\mathrm{b}$ ) differences between $\mathrm{T}_{\mathrm{p}, \mathrm{m}}$ calculated with and without climate corrections on the 1,630 stations with gaps in their data. 


\section{Discussion}

We compiled one of the largest regional stream temperature datasets to address the growing need to understand stream thermal regimes in the context of climate change. We demonstrate that a simple, ecologically meaningful metric, which we term the thermal peak $\left(\mathrm{T}_{\mathrm{p}}\right)$, can be reliably estimated at the regional scale using a few easily accessible explanatory variables.

\subsection{Horizons and limitations in estimating large-scale stream thermal metrics}

Spatiotemporally comprehensive stream temperature datasets are rare because interest in these data is relatively recent and there is little money to support instrumentation at regional or national scales. This lack of data has been recognized as a major limitation for understanding thermal regimes of riverine ecosystems (Arismendi et al., 2012; Ouellet et al., 2020). Existing data typically come from different entities and are not managed according to a predefined regional strategy, precluding broad-scale synthesis and understanding of controls on stream temperature and its subsequent effects on ecosystems and society. To overcome these barriers, we employed a combined empirical approach that allowed us to identify, at the regional scale, a map of summer stream temperature maxima with important implications for aquatic species distributions under climate change. We observed the hottest $T_{p}$ along major rivers and the coldest $T_{p}$ along small rivers and in mountainous regions (Figure 5). The downside of the current approach is that it remains based on interannual metrics. Indeed, the nonconcomitance of the time series does not allow us to compare extreme years (hot vs. cold).

To enable unbiased comparison among stations from time series with gaps, we used a climate correction of $T_{w}$ based on regression with $\mathrm{T}_{\text {air. }}$. The efficacy of regressions between $\mathrm{T}_{\mathrm{w}}$ and $\mathrm{T}_{\text {air }}$ is well-understood (Ducharne, 2008; Segura et al., 2015, Moatar and Gailhard, 2006), and the approach can be easily transferred to other stations and regions. On the other hand, a cautious approach is required for such regressions, because they assume seasonal correlation $\mathrm{T}_{\text {air }}$ and $\mathrm{T}_{\mathrm{w}}$, and can therefore only apply to rivers having natural seasonal dynamics, without dam release, thermal peaking, or major weirs regulating the flow of streams (Bruno et al., 2013; Chandesris et al., 2019; Seyedhashemi et al., 2021; Casado et al., 2013). However, where possible, climate correction makes it possible to significantly reduce the biases in the estimates of $T_{p}$ to metrics based only on observations (Figure 3 ). The biases are particularly reduced when the number of years of observation available is less than four. Beyond this limit, the meteorological variability specific to each year is sufficient to estimate a robust interannual metric $\mathrm{T}_{\mathrm{p}}$, which confirms results obtained by (Jones and Schmidt, 2018). Moreover, climate correction reduces overestimation of $\mathrm{T}_{\mathrm{p}}$, when applied at scale (Figure 6b), reinforcing the importance of taking into account these climatic corrections to temperature metrics even if it only slightly affects the majority of rivers (Isaak et al., 2017)

\subsection{Spatial extrapolation of $T_{p}$ is consistent and best predicted with a random forest model}

All four statistical models achieved similar predictive performance, but the RF model exhibited marginal improvements over the others (Figure 3). The MM approach only slightly improves performance in crossvalidation in comparison with RF (vis-à-vis the NSE criterion), so it is unlikely to be a useful approach in future applications due to its complexity. Our model performances (NSE $=0.75$, RMSE $<2$ ) were of the same order as 
other large scale stream temperature studies found in the literature (cf. Segura et al., 2015; Daigle et al., 2010; Wehrly et al., 2009), suggesting that our approach is reasonable and broadly applicable.

In spatial extrapolation, the $\mathrm{T}_{\mathrm{p}}$ estimates are globally consistent between the models and the same spatial structures are found regardless of the approach used (Figure 5). We observed divergences between the models in particular for $T_{p}$ less than $14^{\circ} \mathrm{C}$ where $A N N$ tends to simulate coldest $T_{p}$ for more reaches compared to other models (Figure 6). Still, because our analysis is limited to 2009-2017, these model differences may diminish as $T_{w}$ measurements grow in time and space.

\subsection{Drivers of thermal peak depend on model structure}

We observed clear divergence of variable importance for the estimation of $T_{p}$ among the ANN, RF, and REG models. The two most relevant variables in RF and REG are catchment area and mean summer air temperature, consistent with other studies (Laanaya et al., 2017; McGarvey et al., 2018). Greater catchment area typically implies larger stream size, and subsequently higher $\mathrm{T}_{\mathrm{p}}$. Large rivers are also more impacted by low flow warming because they are less shaded by riparian vegetation and are less influenced by groundwater inflows. Moreover, longer water travel times in large rivers allow more time for temperature equilibration with the atmosphere compared to small rivers (Beaufort et al., 2019; Mohseni et al., 1998). Importantly, RF had a much more even distribution of variable importances relative to the other models structures, which is likely due to its non-linear structure. In contrast, for ANN, the most important variables were minimum monthly specific discharge (43\%) following by riparian vegetation cover (23\%). Larger minimum flows imply a consistent groundwater supply, leading to cool surface waters in summer (Hannah et al., 2004; Kelleher et al., 2012; Lalot et al., 2015). Similarly, greater riparian vegetation implies greater shading and reduced temperature increases from solar radiation (Dugdale et al., 2018; Loicq et al., 2018; Moore et al., 2013). These differences in relevance between the variables for each model underlines the importance of using several approaches and shows that an approach combining all the models makes it possible to take into account all these divergences between models. We note that some variables used in models for $\mathrm{T}_{\mathrm{p}}$ were not available across the entire hydrographic network for extrapolation. As a result, certain variables could not be used as the base flow index (BFI) whereas they have been successfully used by other studies (Beaufort et al., 2020a; Hill et al., 2013).

\subsection{Air temperature is not an appropriate proxy for stream temperature}

Estimates of $\mathrm{T}_{\mathrm{p}}$ produced by stream temperature were clearly more accurate than those produced by air temperature (Figures 3 and 5). In cross-validation, $\mathrm{T}_{\mathrm{p} \text {,air }}$ overestimated observed $\mathrm{T}_{\mathrm{p}}$ by more than $2^{\circ} \mathrm{C}$, could not differentiate stream temperature among regions (Figure 5), and could not differentiate large rivers from small rivers. This clearly demonstrates that $T_{\text {air }}$ is an inappropriate proxy for $T_{w}$, with important implications for ecological studies, especially those that consider temperature tolerance thresholds of aquatic species. Species distribution models may need to use $T_{\text {air }}$ instead of $T_{w}$ because data from $T_{w}$ are not sufficient in the regions studied (McGarvey et al., 2018). It is therefore important to introduce $T_{w}$ in input of these models rather than $T_{\text {air }}$ in order to limit the biases linked to the poor spatial representativeness of $\mathrm{T}_{\text {air. }}$. Considering hydrological variables can limit these biases and introduce the effects of the size of the catchment on the variability of $T_{w}$ metrics. However, there may be local cooling or warming effects, which can only be understood with field observations. We must therefore continue the 
efforts already started for the acquisition of time series of $\mathrm{T}_{\mathrm{w}}$ and monitoring more streams to obtain better thermal representativeness of hydrosystems.

\section{Conclusion}

Stream thermal regimes are essential controls on aquatic ecosystems, but our understanding of these regimes and thus our ability to adequately manage them accordingly in the context of climate change is limited by data availability and simple metrics applicable at large scales. To address these gaps, we developed a simple, ecologically relevant metric-the thermal peak, $\mathrm{T}_{\mathrm{p}}$ - that can be extrapolated at large scales, even when data are sparse. We developed an innovative climate correction method to reduce biases related to such data sparseness, when applied to summer data. The $\mathrm{T}_{\mathrm{p}}$ provides an important perspective on the magnitude of thermal extremes during summer, but development of additional metrics such as threshold exceedance frequency, duration, and timing will continue to grow our understanding of stream temperature behavior under climate change. However, development of these metrics will require longer and more spatially explicit time series. Hence, we argue that to improve our capacity to manage and benefit from aquatic ecosystems, it is critical to continue and expand our stream temperature measurement networks.

\section{References}

Arismendi, I., Johnson, S. L., Dunham, J. B., Haggerty, R., and Hockman-Wert, D.: The paradox of cooling streams in a warming world: regional climate trends do not parallel variable local trends in stream temperature in the Pacific continental United States, Geophysical Research Letters, 39, 2012.

Arismendi, I., Safeeq, M., Dunham, J. B., and Johnson, S. L.: Can air temperature be used to project influences of climate change on stream temperature?, Environmental Research Letters, 9, 084015, 2014.

Beaufort, A., Moatar, F., Curie, F., Ducharne, A., Bustillo, V., and Thiéry, D.: River Temperature Modelling by Strahler Order at the Regional Scale in the Loire River Basin, France, River Research and Applications, 32, 597609, 10.1002/rra.2888, 2016.

Beaufort, A., Moatar, F., Sauquet, E., Loicq, P., and Hannah, D. M.: Influence of landscape and hydrological factors on stream-air temperature relationships at regional scale, Hydrological Processes, 34, 583-597, 2020a.

Beaufort, A., Moatar, F., Sauquet, E., and Magand, C.: Thermie en rivière : Analyse géostatistique et description de régime : Application à l'échelle de la France, INRAE, 106 pages, 2020b.

Benyahya, L., Caissie, D., St-Hilaire, A., Ouarda, T. B., and Bobée, B.: A review of statistical water temperature models, Canadian Water Resources Journal, 32, 179-192, 2007.

Bishop, C. M.: Pattern recognition and machine learning, springer, 2006.

Breiman, L.: Random forests, Machine learning, 45, 5-32, 2001.

Bruno, M. C., Siviglia, A., Carolli, M., and Maiolini, B.: Multiple drift responses of benthic invertebrates to interacting hydropeaking and thermopeaking waves, Ecohydrology, 6, 511-522, 2013.

Buisson, L., and Grenouillet, G.: Contrasted impacts of climate change on stream fish assemblages along an environmental gradient, Divers. Distrib., 15, 613-626, 2009. 
Bustillo, V., Moatar, F., Ducharne, A., Thiery, D., and Poirel, A.: A multimodel comparison for assessing water temperatures under changing climate conditions via the equilibrium temperature concept: case study of the Middle Loire River, France, Hydrological Processes, 28, 1507-1524, 10.1002/hyp.9683, 2014.

Caissie, D.: The thermal regime of rivers: a review, Freshwater biology, 51, 1389-1406, 2006.

Casado, A., Hannah, D. M., Peiry, J. L., and Campo, A. M.: Influence of dam-induced hydrological regulation on summer water temperature: Sauce Grande River, Argentina, Ecohydrology, 6, 523-535, 2013.

Catalogne, C.: Amélioration des méthodes de prédétermination des débits de référence d'étiage en sites peu ou pas jaugés, Doctorat Ocean Atmosphere Hydrologie, Université Joseph Fourier, Grenoble, 2012.

Chandesris, A., Looy, K. V., Diamond, J. S., and Souchon, Y.: Small dams alter thermal regimes of downstream water, Hydrology and Earth System Sciences, 23, 4509-4525, 2019.

Chang, H., and Psaris, M.: Local landscape predictors of maximum stream temperature and thermal sensitivity in the Columbia River Basin, USA, Science of the Total Environment, 461, 587-600, 2013.

Chenard, J. F., and Caissie, D.: Stream temperature modelling using artificial neural networks: application on Catamaran Brook, New Brunswick, Canada, Hydrological Processes: An International Journal, 22, 3361-3372, 2008.

Conti, L., Comte, L., Hugueny, B., and Grenouillet, G.: Drivers of freshwater fish colonisations and extirpations under climate change, Ecography, 38, 510-519, 2015.

Daigle, A., St-Hilaire, A., Peters, D., and Baird, D.: Multivariate modelling of water temperature in the Okanagan watershed, Canadian Water Resources Journal, 35, 237-258, 2010.

Daufresne, M., Roger, M., Capra, H., and Lamouroux, N.: Long-term changes within the invertebrate and fish communities of the Upper Rhône River: effects of climatic factors, Global Change Biology, 10, 124-140, 2004.

Daufresne, M., Lengfellner, K., and Sommer, U.: Global warming benefits the small in aquatic ecosystems, Proceedings of the National Academy of Sciences, 106, 12788-12793, 2009.

Detenbeck, N. E., Morrison, A. C., Abele, R. W., and Kopp, D. A.: Spatial statistical network models for stream and river temperature in New England, USA, Water Resources Research, 52, 6018-6040, 2016.

DeWeber, J. T., and Wagner, T.: A regional neural network ensemble for predicting mean daily river water temperature, Journal of Hydrology, 517, 187-200, 2014.

Ducharne, A.: Importance of stream temperature to climate change impact on water quality, Hydrology and Earth System Sciences, 12, 797-810, 2008.

Dugdale, S. J., Malcolm, I. A., Kantola, K., and Hannah, D. M.: Stream temperature under contrasting riparian forest cover: Understanding thermal dynamics and heat exchange processes, Science of The Total Environment, 610, 1375-1389, 2018.

Durance, I., and Ormerod, S. J.: Trends in water quality and discharge confound long-term warming effects on river macroinvertebrates, Freshwater Biology, 54, 388-405, 2009.

Elliott, J.: The energetics of feeding, metabolism and growth of brown trout (Salmo trutta L.) in relation to body weight, water temperature and ration size, The Journal of Animal Ecology, 923-948, 1976.

Hannah, D. M., Malcolm, I. A., Soulsby, C., and Youngson, A. F.: Heat exchanges and temperatures within a salmon spawning stream in the Cairngorms, Scotland: seasonal and sub-seasonal dynamics, River Research and 
Heino, J., Virkkala, R., and Toivonen, H.: Climate change and freshwater biodiversity: detected patterns, future trends and adaptations in northern regions, Biological Reviews, 84, 39-54, 2009.

Hill, R. A., Hawkins, C. P., and Carlisle, D. M.: Predicting thermal reference conditions for USA streams and rivers, Freshwater Science, 32, 39-55, 2013.

Hill, R. A., and Hawkins, C. P.: Using modelled stream temperatures to predict macro-spatial patterns of stream invertebrate biodiversity, Freshwater Biology, 59, 2632-2644, 2014.

Hrachowitz, M., Soulsby, C., Imholt, C., Malcolm, I., and Tetzlaff, D.: Thermal regimes in a large upland salmon river: a simple model to identify the influence of landscape controls and climate change on maximum temperatures, Hydrological Processes, 24, 3374-3391, 2010.

Isaak, D. J., Luce, C. H., Rieman, B. E., Nagel, D. E., Peterson, E. E., Horan, D. L., Parkes, S., and Chandler, G. L.: Effects of climate change and wildfire on stream temperatures and salmonid thermal habitat in a mountain river network, Ecological Applications, 20, 1350-1371, 2010.

Isaak, D. J., Wenger, S. J., Peterson, E. E., Ver Hoef, J. M., Nagel, D. E., Luce, C. H., Hostetler, S. W., Dunham, J. B., Roper, B. B., and Wollrab, S. P.: The NorWeST summer stream temperature model and scenarios for the western US: A crowd-sourced database and new geospatial tools foster a user community and predict broad climate warming of rivers and streams, Water Resources Research, 53, 9181-9205, 2017.

Jackson, F. L., Fryer, R. J., Hannah, D. M., Millar, C. P., and Malcolm, I. A.: A spatio-temporal statistical model of maximum daily river temperatures to inform the management of Scotland's Atlantic salmon rivers under climate change, Science of the Total Environment, 612, 1543-1558, 2018.

Jones, N., and Schmidt, B.: Thermal regime metrics and quantifying their uncertainty for North American streams, River Research and Applications, 34, 382-393, 2018.

Kelleher, C., Wagener, T., Gooseff, M., McGlynn, B., McGuire, K., and Marshall, L.: Investigating controls on the thermal sensitivity of Pennsylvania streams, Hydrological Processes, 26, 771-785, 2012.

Kishi, D., Murakami, M., Nakano, S., and Maekawa, K.: Water temperature determines strength of top-down control in a stream food web, Freshwater biology, 50, 1315-1322, 2005.

Lalot, E., Curie, F., Wawrzyniak, V., Baratelli, F., Schomburgk, S., Flipo, N., Piegay, H., and Moatar, F.: Quantification of the contribution of the Beauce groundwater aquifer to the discharge of the Loire River using thermal infrared satellite imaging, Hydrology and Earth System Sciences, 19, 4479-4492, 2015.

Letcher, B. H., Hocking, D. J., O’Neil, K., Whiteley, A. R., Nislow, K. H., and O’Donnell, M. J.: A hierarchical model of daily stream temperature using air-water temperature synchronization, autocorrelation, and time lags, PeerJ, 4, e1727, 2016.

Liaw, A., and Wiener, M.: Classification and regression by randomForest, R news, 2, 18-22, 2002.

Logez, M., Bady, P., and Pont, D.: Modelling the habitat requirement of riverine fish species at the European scale: sensitivity to temperature and precipitation and associated uncertainty, Ecology of Freshwater Fish, 21, 266-282, 2012.

Loicq, P., Moatar, F., Jullian, Y., Dugdale, S. J., and Hannah, D. M.: Improving representation of riparian vegetation shading in a regional stream temperature model using LiDAR data, Science of the total environment, 624, 480-490, 2018.

Malard, F., Tockner, K., DOLE-OLIVIER, M. J., and Ward, J.: A landscape perspective of surface-subsurface hydrological exchanges in river corridors, Freshwater Biology, 47, 621-640, 2002. 
McGarvey, D. J., Menon, M., Woods, T., Tassone, S., Reese, J., Vergamini, M., and Kellogg, E.: On the use of climate covariates in aquatic species distribution models: are we at risk of throwing out the baby with the bath water?, Ecography, 41, 695-712, 2018.

Miller, S. W., Wooster, D., and Li, J.: Resistance and resilience of macroinvertebrates to irrigation water withdrawals, Freshwater Biology, 52, 2494-2510, 2007.

Moatar, F., Miquel, J., and Poirel, A.: A quality-control method for physical and chemical monitoring data. Application to dissolved oxygen levels in the river Loire (France), Journal of Hydrology, 252, 25-36, 10.1016/s0022-1694(01)00439-5, 2001.

Moatar, F., and Gailhard, J.: Water temperature behaviour in the River Loire since 1976 and 1881, Comptes Rendus Geoscience, 338, 319-328, 10.1016/j.crte.2006.02.011, 2006.

Mohseni, O., Stefan, H. G., and Erickson, T. R.: A nonlinear regression model for weekly stream temperatures, Water Resources Research, 34, 2685-2692, 1998.

Moore, R., Nelitz, M., and Parkinson, E.: Empirical modelling of maximum weekly average stream temperature in British Columbia, Canada, to support assessment of fish habitat suitability, Canadian Water Resources Journal, 38, 135-147, 2013.

Nash, J. E., and Sutcliffe, J. V.: River flow forecasting through conceptual models part I-A discussion of principles, Journal of hydrology, 10, 282-290, 1970.

Ojanguren, A., and Brañta, F.: Thermal dependence of swimming endurance in juvenile brown trout, Journal of Fish Biology, 56, 1342-1347, 2000.

Olden, J. D., and Jackson, D. A.: Illuminating the "black box": a randomization approach for understanding variable contributions in artificial neural networks, Ecological modelling, 154, 135-150, 2002.

Olden, J. D., Joy, M. K., and Death, R. G.: An accurate comparison of methods for quantifying variable importance in artificial neural networks using simulated data, Ecological modelling, 178, 389-397, 2004.

Olden, J. D., and Naiman, R. J.: Incorporating thermal regimes into environmental flows assessments: modifying

510 dam operations to restore freshwater ecosystem integrity, Freshwater Biology, 55, 86-107, 2010.

Ouellet, V., St-Hilaire, A., Dugdale, S. J., Hannah, D. M., Krause, S., and Proulx-Ouellet, S.: River temperature research and practice: Recent challenges and emerging opportunities for managing thermal habitat conditions in stream ecosystems, Science of The Total Environment, 139679, 2020.

Pella, H., Lejot, J., Lamouroux, N., and Snelder, T.: Le réseau hydrographique théorique (RHT) français et ses attributs environnementaux, Géomorphologie: relief, processus, environnement, 18, 317-336, 2012.

Pratt, B., and Chang, H.: Effects of land cover, topography, and built structure on seasonal water quality at multiple spatial scales, Journal of hazardous materials, 209, 48-58, 2012.

Quintana-Segui, P., Le Moigne, P., Durand, Y., Martin, E., Habets, F., Baillon, M., Canellas, C., Franchisteguy, L., and Morel, S.: Analysis of near-surface atmospheric variables: Validation of the SAFRAN analysis over

France, Journal of applied meteorology and climatology, 47, 92-107, 2008.

Sauquet, E., Gottschalk, L., and Leblois, E.: Mapping average annual runoff: a hierarchical approach applying a stochastic interpolation scheme, Hydrological sciences journal, 45, 799-815, 2000.

Sauquet, E.: Mapping mean annual river discharges: geostatistical developments for incorporating river network dependencies, Journal of Hydrology, 331, 300-314, 2006. 
Sauquet E., Gottschalk L., and Krasovskaia I. Estimating mean monthly runoff at ungauged locations: an application to France. Hydrology Research, 39, 403-423, 2008.

Sauquet, E., and Catalogne, C.: Comparison of catchment grouping methods for flow duration curve estimation at ungauged sites in France, Hydrology and Earth System Sciences Discussions, 15, p. 2421-p. 2435, 2011.

Segura, C., Caldwell, P., Sun, G., McNulty, S., and Zhang, Y.: A model to predict stream water temperature across the conterminous USA, Hydrological Processes, 29, 2178-2195, 2015.

Seyedhashemi, H., Moatar, F., Vidal, J.-P., Diamond, J. S., Beaufort, A., Chandesris, A., and Valette, L.: Thermal signatures identify the influence of dams and ponds on stream temperature at the regional scale, Science of The Total Environment, 766, 142667, https://doi.org/10.1016/j.scitotenv.2020.142667, 2021.

Sohrabi, M. M., Benjankar, R., Tonina, D., Wenger, S. J., and Isaak, D. J.: Estimation of daily stream water temperatures with a Bayesian regression approach, Hydrological Processes, 31, 1719-1733, 2017.

Steel, E. A., Beechie, T. J., Torgersen, C. E., and Fullerton, A. H.: Envisioning, quantifying, and managing thermal regimes on river networks, BioScience, 67, 506-522, 2017.

Tisseuil, C., Vrac, M., Grenouillet, G., Wade, A. J., Gevrey, M., Oberdorff, T., Grodwohl, J.-B., and Lek, S.: Strengthening the link between climate, hydrological and species distribution modeling to assess the impacts of climate change on freshwater biodiversity, Science of the total environment, 424, 193-201, 2012.

Tsang, Y. P., Infante, D. M., Stewart, J., Wang, L., Tingly III, R. W., Thornbrugh, D., Cooper, A. R., and Daniel, W. M.: StreamThermal: A software package for calculating thermal metrics from stream temperature data, Fisheries, 41, 548-554, 2016.

Valette, L., Piffady, J., Chandesris, A., and Souchon, Y.: SYRAH-CE: description des données et modélisation du risque d'altération hydromorphologique des cours d'eau pour l'état des lieux DCE, Rapport Technique OnemaIrstea, 2012.

van Vliet, M. T. H., Yearsley, J. R., Franssen, W. H. P., Ludwig, F., Haddeland, I., Lettenmaier, D. P., and Kabat, P.: Coupled daily streamflow and water temperature modelling in large river basins, Hydrology and Earth System Sciences, 16, 4303-4321, 10.5194/hess-16-4303-2012, 2012.

Vidal, J. P., Martin, E., Franchistéguy, L., Baillon, M., and Soubeyroux, J. M.: A 50-year high-resolution atmospheric reanalysis over France with the Safran system, International Journal of Climatology, 30, 1627-1644, 2010.

Wehrly, K. E., Brenden, T. O., and Wang, L.: A comparison of statistical approaches for predicting stream temperatures across heterogeneous landscapes 1, JAWRA Journal of the American Water Resources Association, 45, 986-997, 2009.

Westhoff, M., Savenije, H., Luxemburg, W., Stelling, G., Van de Giesen, N., Selker, J., Pfister, L., and Uhlenbrook, S.: A distributed stream temperature model using high resolution temperature observations, Hydrology and Earth System Sciences, 11, 1469-1480, 2007.

Venables, W. N. and Ripley, B. D.: Modern Applied Statistics with S. Fourth Edition. Springer, New York. ISBN 0-387-95457-0, 2002.

Wolter, C.: Temperature influence on the fish assemblage structure in a large lowland river, the lower Oder River, Germany, Ecology of Freshwater Fish, 16, 493-503, 2007.

Yearsley, J.: A grid-based approach for simulating stream temperature, Water Resources Research, 48, 2012. 